\title{
Aziridine and azirine carboxylic esters
}

\author{
Binne Zwanenburg and Lambertus Thijs \\ Department of Organic Chemistry, NSR Center for Molecular Structure, Design and \\ Synthesis, University of Nijmegen, Toernooiveld, 6525 ED Nijmegen, The Netherlands.
}

\begin{abstract}
A convenient synthesis of aziridine-2-carboxylic esters of high enantiopurity from the corresponding oxiranecarboxylic esters is described. Ring opening reactions of these aziridine esters with various nucleophilic agents constitute a versatile entrée to functionalized amino acid derivatives. The synthesis of $2 H$-azirine-2-carboxylic esters from aziridine-2-carboxylic esters by an eliminative reaction is reported. An alternative preparation of $2 H$-azirine-2-carboxylic esters involves an alkaloid mediated synthesis from the oxime tosylates of $\beta$-keto esters by a modified Neber reaction.
\end{abstract}

Aziridine-2-carboxylic esters are of interest in view of their structural relationship with $\alpha$ - as well as $\beta$-amino acids and the intrinsic high reactivity of the three-membered ring. Little attention has been paid to these aziridine-2-carboxylates, despite the vast amount of work reported on the synthesis and reactivity of aziridines in general(1). A few syntheses of aziridine-2-carboxylic esters have been described(2), but most of these lead to N-substituted compounds, are non-stereospecific or have a limited scope. We developed(3) a general method for the synthesis of either racemic or optically active aziridine-2-carboxylic esters 1 . These starting materials can readily be synthesized in high enantiopurity from appropriate allylic alcohols by Sharpless epoxidation(4) followed by oxidation of the 2,3-epoxy alcohols to the corresponding carboxylic acids using either ruthenium tetroxide or a two-step process consisting of Swern oxidation to the aldehyde and subsequent oxidation with sodium chlorite to the carboxylic acid stage(3). The synthetic sequence for the conversion of oxirane-2-carboxylic esters $\underline{2}$ into aziridine-2-carboxylic esters 1 is outlined in Scheme 1.

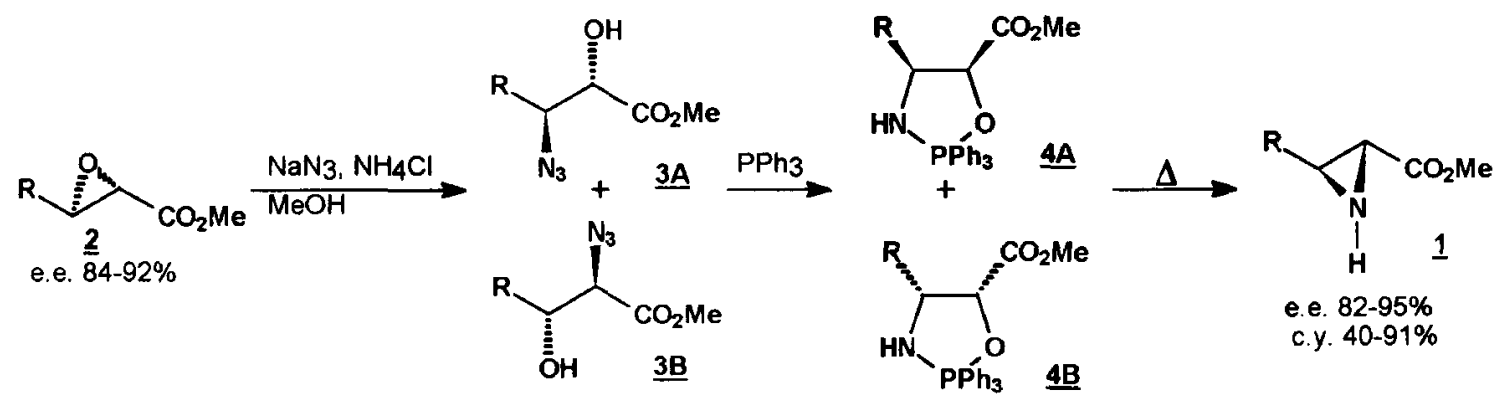

Scheme 1

Treatment of epoxy esters $\underline{\mathbf{2}}$ with sodium azide in an alcoholic solvent containing ammonium chloride (an essential addendum) results in ring opening in an $\mathrm{S}_{\mathrm{N}} 2$ fashion. In most cases, a mixture of the two possible regioisomeric azido alcohols $\underline{\mathbf{3 A}}$ and $\underline{\mathbf{B B}}$ in a ratio of approximately $2: 3$ is obtained from 3-alkyl substituted oxirane esters 2 . This mixture of azido alcohols can be used as such in the next step of the sequence, involving the treatment with triphenylphosphine. The intermediate oxazaphospholidines $\underline{4}$ can be isolated in crude form simply by removal of the solvent and subsequently be subjected to bulb-to bulb distillation to produce the aziridine esters $\underline{1}$. The recommended method for conversion of intermediates $\underline{4}$ into the ultimate products $\underline{1}$ is heating them in acetonitrile or dimethylformamide(3). The stereochemical configuration of both carbon atoms of the aziridine ring is inverted in comparison with the starting epoxide ester $\mathbf{2}$. The structure of intermediate $\underline{4}$, as established by an $\mathrm{X}$-ray analysis $(3,5)$, clearly reveals that the first reaction results in inversion at the carbon 
atom attacked by the azide ion. Cleavage of the P-N bond in $\mathbf{4}$ leads to an intermediate dipolar species which undergoes intramolecular displacement of triphenylphosphine oxide and concomitant aziridine formation (Scheme 2). This ring closure takes place with inversion of configuration at the carbon atom bearing the leaving group $\left(\mathrm{Ph}_{3}{ }^{+}-\mathrm{O}\right)$. It is of importance to note that both azide alcohols $\underline{\mathbf{B A}}$ and $\underline{\mathbf{3 B}}$ undergo this Staudinger reaction producing the same ultimate product.

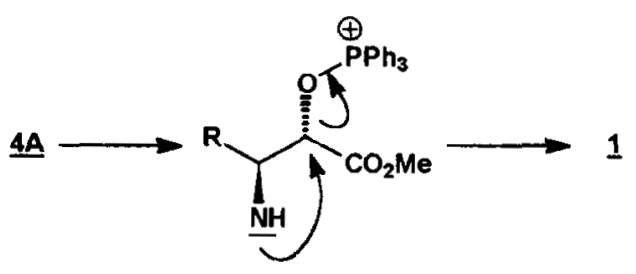

Scheme 2

The above method involving ring opening of an oxirane carboxylic ester with azide, followed by a ring closure to the corresponding aziridine esters by treatment with triphenylphosphine, was employed for the synthesis(6) of (2S,3S)-(+)-aziridine-2,3-dicarboxylic acid $\underline{\mathbf{5}}$, a natural product isolated(7) from Streptomyces MD 398-A1 (Scheme 3).<smiles>[R16]C1(C(=O)OCC)OC1C(=O)OCC</smiles>

1) $\mathrm{Me}_{3} \mathrm{SiN}_{3}, \mathrm{EtOH}$
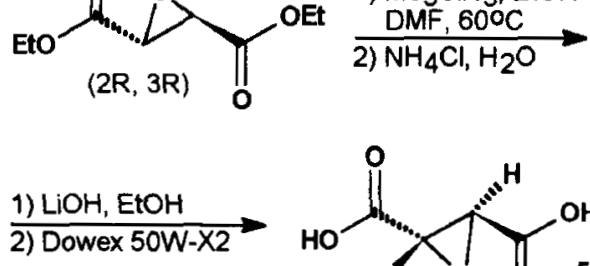<smiles>O=C(O)[C@H]1N[C@H]1C(=O)O</smiles>

$(+)-(2 S, 3 S), 69 \%$ enantiopure<smiles>CCOC(=O)[C@@H](N)[C@H](O)C(=O)OCC</smiles>

(2R, 3S), $72 \%$ $[+(2 R, 3 R), 8 \%]$

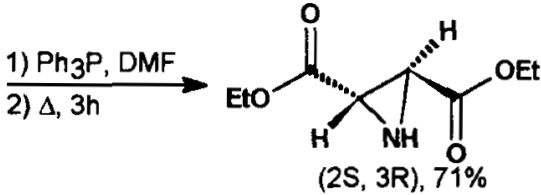

e.e.: $95 \%$

\section{Scheme 3}

Aziridine-2-carboxylic acids behave as normal $\alpha$-amino acids in the reaction with triethylborane to give(8) boroxazolidones $\underline{6}$ (Scheme 4).

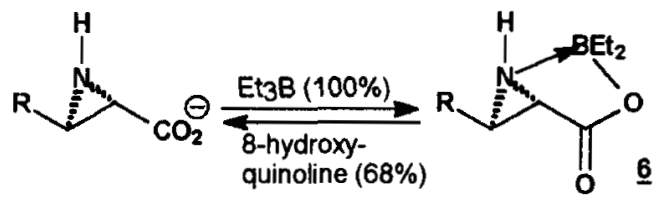

Scheme 4

Ring opening reactions of 3-aryl-aziridine-2-carboxylic esters constitute an attractive entrée to functionalized phenylalanine derivatives(9). For example, reaction of aziridine ester 1 with thiophenol gives amino acid ester $\underline{7}$ of high enantiopurity. Treatment with indole leads to $\beta$-indolyl amino ester $\underline{\boldsymbol{z}}$ and reaction with acetic acid

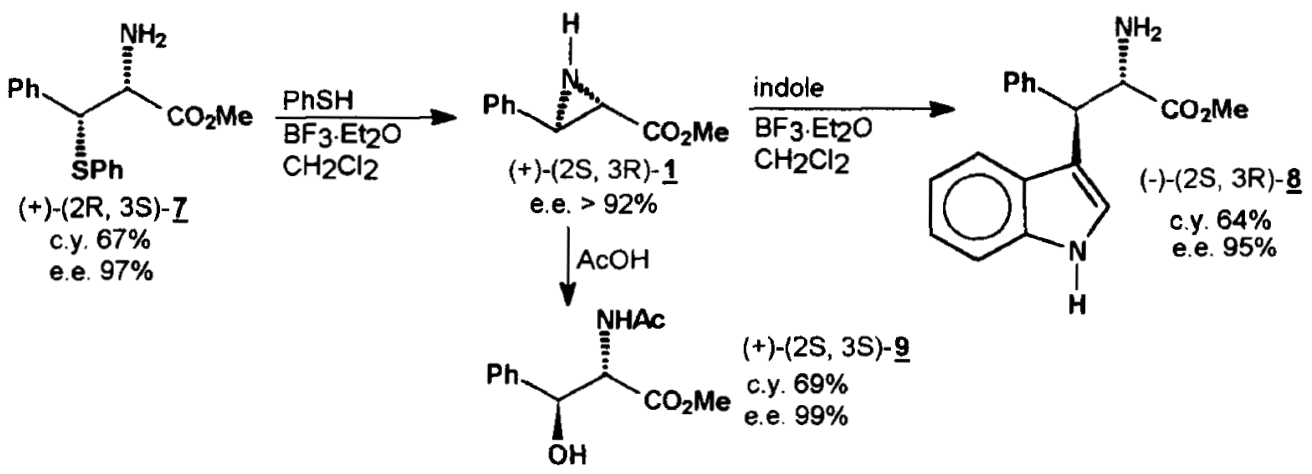


produces initially a $\beta$-acetoxy-phenylalanine methyl ester which spontaneously rearranges to enantiopure $\beta$ hydroxy-N-acetyl-phenylalanine ester $\mathbf{9}$ (Scheme 5).

An interesting ring expansion was found(10) when alkyl substituted aziridine esters were treated with acetonitrile in the presence of boron trifluoride etherate (Scheme 6). The imidazolines 10 obtained have a cisrelationship between the alkyl group and the ester function, implying that this reaction proceeds via initial attack of acetonitrile at $\mathrm{C}-3$ of the three-membered ring with inversion of configuration. On continued exposure to moisture the imidazolines $\underline{10}$ gradually hydrolyze to $\alpha, \beta$-diamino-carboxylic esters $\underline{11}$.

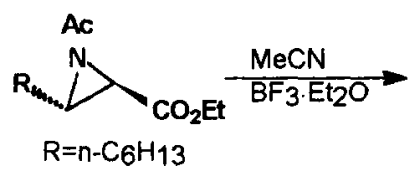

\section{Scheme 6}

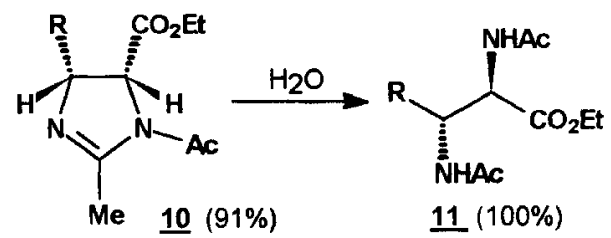

$11(100 \%)$

An interesting question is whether it is possible to convert aziridine esters $\underline{1}$ into azirine-2-carboxylic esters $\underline{13}$. A logical route to $\underline{13}$ seemed an elimination reaction of $\mathrm{N}$-halo derivatives of $\underline{1}$. Treatment of esters $\underline{1}$ with tert-butyl hypochlorite produces the desired $\mathrm{N}$-chloro compounds 12 in high yield. However, the subsequent dehydrochlorination reaction could only be accomplished in moderate yield to give $2 H$-azirine-2-carboxylic ester $\underline{13}$ along with some dechlorination to ester $\underline{1}$ (Scheme 7). A surprisingly simple and high yielding method(12) for the conversion of $\underline{\mathbf{2}}$ into $\underline{\mathbf{1 3}}$ turned out to be a modified Swern oxidation (Scheme 7). Remarkably, both methods only lead to azirine ester 13 and not to the isomeric $2 \mathrm{H}$-azirine-3-carboxylic esters. A mechanistic study to account for this result is currently ongoing in the author's laboratory.

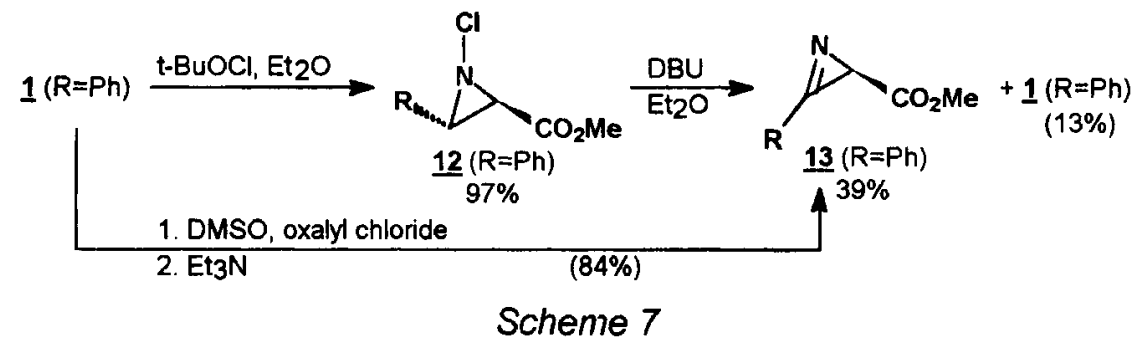

An attractive alternative synthesis(13) of azirine esters $\underline{13}$ is a modified Neber reaction of oxime tosylates $\underline{14}$ as depicted in Scheme 8. By using the chiral base quinidine an asymmetric synthesis of 13 could be realized. In this asymmetric version of the reaction, the nature of the solvent is essential. In toluene the e.e. of $13(\mathrm{R}=\mathrm{Pr})$ amounts to $80 \%$, where in acetonitrile, ether, or dichloromethane the e.e varies from 8 to $47 \%$. Also a catalytic version of this asymmetric Neber reaction was developed by using solid potassium carbonate as the regenerating auxiliary base.

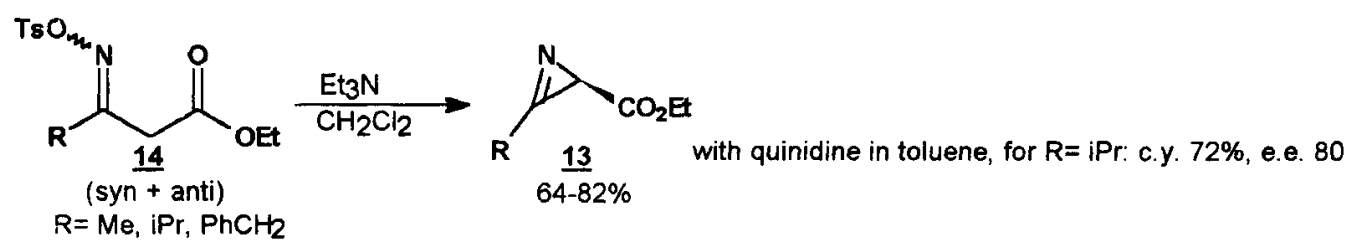

\section{Scheme 8}

It was found that cinchona alkaloids give the best results, whereas bases lacking a hydroxyl function (e.g., sparteine and brucine) show no asymmetric induction at all.

Aziridine-2-carboxylic esters are interesting substrates for further synthetic elaboration. A recent result(14) is depicted in Scheme 9. Aziridine ester 15, prepared from either serine or threonine, can readily be converted into aziridine carbinols $\underline{16}$ which in turn on treatment with diborane give the chiral oxazaborolidines $\underline{17}$ (the 
three-membered ring analog of Corey's catalyst derived from $\alpha, \alpha$-diphenyl-2-pyrrolidinemethanol). The use of catalyst 16 in the asymmetric ketone reduction gives the corresponding alcohols in high optical yields (Scheme 9).
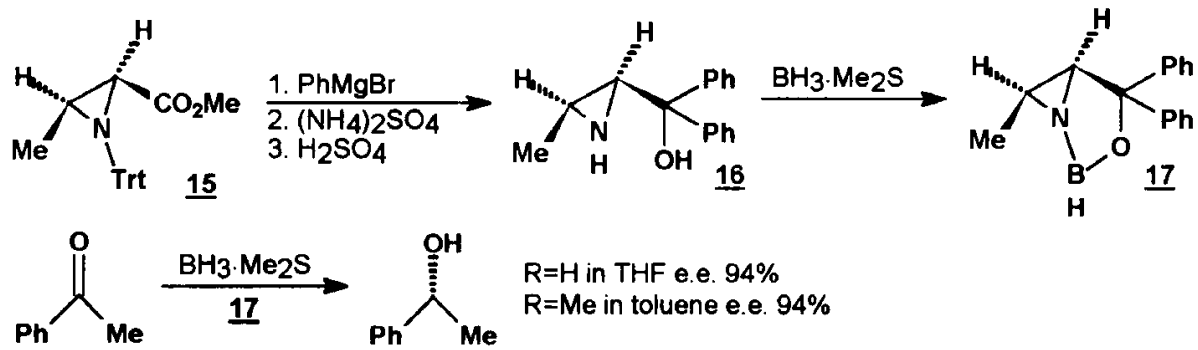

Scheme 9

Finally, appropriately substituted aziridines can be used to prepare enantiopure phospholipid analogs containing amides linkages which show a unique aggregation behavior, viz. expression of molecular chirality on the supramolecular level(15).

\section{REFERENCES}

1. P.E. Fanta, in "Heterocyclic Compounds with Three and Four-membered Rings" Part 1, A. Weissberger, ed. Wiley Interscience, New York, 1964, pp.528; J.A. Deyrup, in "Small Ring Heterocycles", Part 1. A. Hassner, ed. Wiley Interscience, New York, 1983, pp. 11.

2. For a review, see: K. Okawa, K. Nakajima and T. Tanaka, J. Synth. Org. Chem. Jap, . 42, 390 (1984).

3. J. Legters, L. Thijs and B. Zwanenburg, Tetrahedron Lett., 30, 4881 (1989); Idem, Recl. Trav. Chim. Pays-Bas, 111, 1 (1992).

4. Y. Gao, R.M. Hanson, J.M. Klunder, S.Y. Ko, H. Masamune and K.B. Sharpless, J. Am. Chem. Soc., 109, 5765 (1987).

5. J.J.M. Smits, P.T. Beurskens, L. Thijs, A.A.W.M. van Loon and B. Zwanenburg, J. Cryst. Spectr. Res., $18,625(1988)$.

6. J. Legters, L. Thijs and B. Zwanenburg, Tetrahedron Lett., 28, 5287 (1991).

7. H. Naganawa et al., J. Antibiot., 28, 828 (1975).

8. J. Legters, L. Thijs and B. Zwanenburg, Recl. Trav. Chim. Pays-Bas, 111, 211 (1992).

9. J. Legters, L. Thijs and B. Zwanenburg, Recl. Trav. Chim. Pays-Bas, 111, 16 (1992).

10. J. Legters, J.G.H. Willems, L. Thijs and B. Zwanenburg, Recl. Trav. Chim. Pays-Bas, 111, 59 (1992). Compare for similar reactions with oxiranecarboxylic esters and acetonitrile: J. Legters, E. van Dienst, L. Thijs and B. Zwanenburg, Recl. Trav. Chim. Pays-Bas, 111, 69 (1992).

11. J. Legters, L. Thijs and B. Zwanenburg, Recl. Trav. Chim. Pays-Bas, 111, 75 (1992).

12. L. Gentilucci, L. Thijs and B. Zwanenburg, to be published.

13. M.M.H. Verstappen, G.J.A. Ariaans an B. Zwanenburg, to be published.

14. J.G.H. Willems, F.J. Dommerholt, J.B. Hammink, A.M. Vaarhorst, L. Thijs and B. Zwanenburg, Tetrahedron Lett., in press (1995).

15. N.A.J.M. Sommerdijk, P.J.J.A. Buijnsters, A.M.A. Pistorius, M. Wang, M.C. Feiters, R.J.M. Nolte and B. Zwanenburg, J. Chem. Soc, Chem. Commun., 1941 (1994). 